\title{
The beneficial effect of the sap of Acer mono in an animal with low-calcium diet-induced osteoporosis-like symptoms
}

\author{
Geun-Shik Lee ${ }^{1}$, Hyuk-Soo Byun ${ }^{1}$, Man-Hee Kim ${ }^{1}$, Bo-Mi Lee ${ }^{1}$, Sang-Hwan Ko ${ }^{1}$, Eui-Man Jung ${ }^{1}$, \\ Ki-Seob Gwak ${ }^{2}$, In-Gyu Choi ${ }^{2}$, Ha-Young Kang ${ }^{3}$, Hyun-Jin Jo ${ }^{3}$, Hak-Ju Lee ${ }^{3}$ and Eui-Bae Jeung ${ }^{1} *$ \\ ${ }^{1}$ Laboratory of Veterinary Biochemistry and Molecular Biology, College of Veterinary Medicine, Chungbuk National University, \\ Cheongju, Chungbuk 361-763, Republic of Korea \\ ${ }^{2}$ Department of Forest Sciences, College of Agriculture \& Life Sciences, Seoul National University, Seoul 151-921, \\ Republic of Korea \\ ${ }^{3}$ Division of Wood Chemistry and Microbiology, Department of Forest Products, Korea Forest Research Institute, Seoul 130-712, \\ Republic of Korea
}

(Received 18 September 2007 - Revised 18 January 2008 - Accepted 12 February 2008 - First published online 1 April 2008)

\begin{abstract}
The sap of Acer mono has been called 'bone-benefit-water' in Korea because of its mineral and sugar content. In particular, the calcium concentration of the sap of $A$. mono is 37.5 times higher than commercial spring water. In the current study, we examined whether $A$. mono sap could improve or prevent osteoporosis-like symptoms in a mouse model. Male mice ( 3 weeks old) were fed a low-calcium diet supplemented with 25,50 or $100 \%$ A. mono sap, commercial spring water or a high calcium-containing solution as a beverage for 7 weeks. There were no differences in weekly weight gain and food intake among all the groups. Mice that were given a low-calcium diet supplemented with commercial spring water developed osteoporosis-like symptoms. To assess the effect of sap on osteoporosis-like symptoms, we examined serum calcium concentration, and femur density and length, and carried out a histological examination. Serum calcium levels were significantly lower in mice that received a lowcalcium diet supplemented with commercial spring water (the negative control group), and in the $25 \%$ sap group compared to mice fed a normal diet, but were normal in the 50 and $100 \%$ sap and high-calcium solution groups. Femur density and length were significantly reduced in the negative control and $25 \%$ sap groups. These results indicate that a $50 \%$ sap solution can mitigate osteoporosis-like symptoms induced by a lowcalcium diet. We also examined the regulation of expression of calcium-processing genes in the duodenum and kidney. Duodenal TRPV6 and renal calbindin- $D 9 k$ were up-regulated dose-dependently by sap, and the levels of these factors were higher than those attained in the spring water-treated control. The results demonstrate that the sap of A. mono ameliorates the low bone density induced by a low-calcium diet, most likely by increasing calcium ion absorption.
\end{abstract}

Acer mono: Calcium-processing genes: Osteoporosis: Sap

Sap is the fluid transported in the xylem cells or phloem sieve tube elements of a plant. Sap consists primarily of water, but also contains mineral elements, sugars, hormones and other nutrients. Other liquid components found in plants or that are exuded by plants, such as latex, resins and mucilage, are sometimes incorrectly referred to as sap ${ }^{(1)}$. Acer mono is a rounded, deciduous tree with five to seven bright green, almost heart-shaped, lobular leaves that turn yellow in autumn. Yellow flowers appear on erect umbels with these leaves, but may also appear without them. The sap of A. mono contains sugar, and can be ingested directly as a drink, or concentrated into a syrup by boiling ${ }^{(2)}$ and then used as a sweetener. In Korea, the sap of $A$. mono has been called 'bone-benefit-water' because of its abundant calcium and magnesium ion content. The medicinal uses of $A$. mono include the leaves as an irritant and the bark as an astringent $^{(3)}$, however, the pharmacological effect of the sap on bone health has not been examined.

The most common abnormality of bone is osteoporosis, which is a decrease in the density of the bone mass that causes thinning and weakening of the bone. There are two main categories of osteoporosis: type I and type II. Type I osteoporosis occurs only in post-menopausal women, and is due to oestrogen deficiency. Type II osteoporosis occurs in both men and women (about two times more frequently in women), and is due to ageing and calcium deficiency. In animal models, a low-calcium diet leads to the development of radiologic rickets and histologic features of osteomalacia ${ }^{(4)}$. These symptoms were defined as osteoporosis-like symptoms in the present study.

To clarify the potential therapeutic nature of 'bonebenefit-water', an animal model of low-calcium diet-induced

Abbreviations: CaBP-9k, calbindin-D9k; 1,25-(OH) $)_{2} \mathrm{D}_{3}$, 1,25-dihydroxyvitamin D3; PTH, parathyroid hormone; TRPV5, transient receptor potential vanilloid 5; TRPV6, transient receptor potential vanilloid 6.

* Corresponding author: Dr Eui-Bae Jeung, fax +82 43267 3150, email ebjeung@chungbuk.ac.kr 
osteoporosis-like symptoms has been generated. Using this model, the effect of sap on the active calcium transport system has also been examined. Calcium ions are actively absorbed from the duodenum and reabsorbed in kidney. In the calcium active transport system, several proteins mediate calcium influx, transfer through the cytosol and extrusion into the bloodstream. In the active calcium-transporting organs, these steps are carried out by calcium entry channel proteins of the outer cell membrane, cytosolic buffering or transfer proteins, and excretory pump proteins ${ }^{(5-7)}$. Two highly selective calcium channels located in the apical cell membrane are the main portals of calcium ion entry, transient receptor potential vanilloid 6 (TRPV6) and 5 (TRPV5). Calbindin-D9k (CaBP-9k) is an intracellular calcium ionbinding protein that is thought to participate in shuttling calcium ions from the apical to the basolateral membrane, where calcium ions are extruded. However, the proteins involved in intracellular calcium transport vary somewhat depending on the tissue. In the epithelial cells of the duodenum, the transport pathway involves calcium entry primarily through specialized TRPV6 channels, and is highly dependent on intracellular free-calcium concentration. Maintenance of the 'open' state of TRPV6 requires the constant buffering action of intracellular calcium-binding proteins. In mammalian intestinal cells, CaBP-9k is the major intracellular calcium-binding protein. The final step of extrusion of calcium into the blood requires ATP. In the kidney, trans-cellular calcium ion transport is carried out by cells lining the distal part of the nephron. Calcium ion entry is facilitated by TRPV5 in the apical membrane. Calcium then binds CaBP-9k and diffuses through the cytosol to the basolateral membrane, where it is extruded, directly or via CaBP-9k, by excretory pump proteins ${ }^{(6)}$.

In the current study, we examined the effect of the sap of A. mono on osteoporosis-like symptoms. Mice were fed a low-calcium diet to induce osteoporosis-like symptoms during their growth stage (from 3 to 10 weeks of age). Solutions of increasing percentages of sap, commercial spring water or a high-calcium-content solution were supplied to the mice, and after 7 weeks, bone mineral density and length, and the osteoid thickness of the femur and tibia were analysed. We also examined the expression of duodenal and renal calcium-processing genes. Serum calcium and parathyroid hormone (PTH) levels were examined as markers of the development of osteoporosis-like symptoms in the mice.

\section{Materials and methods}

\section{Mineral concentration of the sap of Acer mono}

The mineral contents of $A$. mono sap and commercial spring water (Samdasu, Jeju Special Self-governing Province Development Corp., Jeju-si, Jeju-do, Korea) were analysed using an inductively coupled plasma emission spectrometer (ICPS-1000 IV; Shimadzu, Tokyo, Japan). All samples (10 ml) were digested with the addition of $20 \mathrm{ml}$ nitric acid to remove all organic matter, reduced in volume with heating, filtered through no. 42 filter paper (Whatman, Maidstone, UK), and then diluted to a final volume of $50 \mathrm{ml}$ before being processed by an inductively coupled plasma emission spectrometer.

\section{Animals and treatments}

Male ICR mice (3 weeks old) were obtained from KOATECH (Pyeongtaek-si, Gyeonggi-do, Korea). All animals were housed in polycarbonate cages and acclimatized to an environmentally controlled room $\left(23 \pm 2^{\circ} \mathrm{C}\right.$, relative humidity $50 \pm 10 \%$, frequent ventilation and $12 \mathrm{~h}$ light/dark cycle) prior to use. Thirty mice were divided into six groups (five in each group). Osteoporosis-like symptoms were induced in five groups by feeding with a low-calcium diet (AIN-76A purified rodent diet with $1 \%$ phosphorus and $0.02 \%$ calcium, DYET 113294; Dyets Inc., Bethlehem, PA, USA) for 7 weeks. One group was fed a normal diet (AIN-76A purified rodent diet with $0.8 \%$ phosphorus and $1.1 \%$ calcium, DYET \#113295; Dyet Inc.; normal group) for the same period of time.

To assess the preventative effect of $A$. mono sap on osteoporosis-like symptoms, a daily total of $30 \mathrm{ml}$ commercial spring water (negative control group), or a solution of 25 , 50 or $100 \%$ sap, or a high-calcium-content rescue solution ( $7.5 \mathrm{mM}-\mathrm{CaCl}_{2}$ and $3.0 \mathrm{~mm}-\mathrm{NaH}_{2} \mathrm{PO}_{4}$ based on the KrebsRinger buffer, rescue group) were restrictively supplied to the mice from 3 to 10 weeks of age. Body weights were measured weekly for the duration of the experiment. The Ethics Committee of the Chungbuk National University approved all experimental procedures and use of animals.

\section{Bone mineral density and histomorphometry}

Mice were killed at 10 weeks of age by $\mathrm{CO}_{2}$ inhalation. The hind legs were removed and fixed in a $10 \%$ neutralized formalin solution for $3 \mathrm{~d}$. The legs were then washed with water, and the skin and muscle were eliminated. The femur was dried overnight and bone mineral density was analysed using a Direct View CR 500 (Eastman Kodak Co., Rochester, NY, USA). The tibia was decalcified using Plank-Rycholo's solution, and the bone was embedded in paraffin, sectioned and deparaffinized in xylene. Sections were hydrated in a series of descending ethanol concentrations, then stained with haematoxylin and subjected to histomorphometric analyses using light microscopy. Osteoid thickness was measured at the centre point of the tibia.

\section{Real-time PCR using TaqMan ${ }^{\mathrm{TM}}$ Probe}

Total RNA was prepared from the duodenum and kidney using the TRIzol reagent (Invitrogen, Carlsbad, CA, USA). First stand complementary DNA (cDNA) was prepared by subjecting total RNA $(1 \mu \mathrm{g})$ to reverse transcription using mMLV RT (Invitrogen Life Technologies Inc.) and random primers ( 9 mer; TaKaRa Bio. Inc., Otsu, Shiga, Japan) ${ }^{(8,9)}$. Real-time PCR was performed in a $20 \mu \mathrm{l}$ reaction volume containing $10 \mu \mathrm{l}$ TaqMan Universal PCR Master Mix (Applied Biosystems, Foster, CA, USA), $1 \mu \mathrm{l}$ $20 \times$ Assays-on-Demand $^{\mathrm{TM}}$ Gene Expression Assay Mix (Applied Biosystems; TRPV6, Mm00499069_m1, NM_022413.2; TRPV5, Mm01166029_m1, NM_001007572.2; CaBP-9k, Mm00486654_m1, NM_009789.2; HPRT1, Mm00446968_m1, NM_013556.2) and $3 \mu l$ cDNA. Amplification was carried out using a 7300 Real-Time PCR System (Applied Biosystems) and the following cycle parameters: initial denaturation at $50^{\circ} \mathrm{C}$ for $2 \mathrm{~min} ; 90^{\circ} \mathrm{C}$ for $10 \mathrm{~min}$; forty cycles of denaturation at $95^{\circ} \mathrm{C}$ for $15 \mathrm{~s}$; annealing and extension at $60^{\circ} \mathrm{C}$ 
for 1 min. Expression levels were determined using RQ software (Applied Biosystems). The expression of TRPV6, TRPV5 and $C a B P-9 k$ was normalized to that of HPRT1.

\section{Biochemical and hormonal analysis}

Blood was collected from each mouse into serum separator tubes and subjected to centrifugation at $3000 \mathrm{rpm}$ for $10 \mathrm{~min}$. Serum calcium levels were determined using ASAN Ca-Lq Reagents (Asanpharm, Kyeonggido, Korea). Serum PTH levels were measured using a Mouse Intact PTH ELISA Kit (ALPCO Diagnostics, Salem, NH, USA), according to manufacturer's instructions.

\section{Data analysis}

Data were analysed by non-parametric one-way ANOVA using the Kruskal-Wallis test, followed by Dunnett's test for multiple comparisons to the negative control group. Data were ranked according to these tests. Statistical analysis was performed using SPSS for Windows (SPSS Inc., Chicago, IL, USA). $P<0.05$ was considered statistically significant.

\section{Results}

\section{The mineral content of Acer mono sap}

The concentration of sixteen mineral ions was measured in the sap of $A$. mono and commercial spring water. The potassium, calcium and magnesium levels of sap were 16, 37 and 3.9 times higher than commercial spring water, respectively, while the level of sodium in sap was 0.68 times lower (Table 1). A small amount of silicon was detected in both solutions. Manganese was detected only in the sap, and iron was detected only in commercial spring water. No other minerals were detected in either liquid.

Table 1. Mineral content (mg/l) of the sap of Acer mono and commercial spring water

(Mean values with their standard errors)

\begin{tabular}{|c|c|c|c|c|c|}
\hline & \multicolumn{2}{|c|}{$\begin{array}{l}\text { Commercial } \\
\text { spring water }\end{array}$} & \multicolumn{2}{|c|}{ Sap of $A$. mono } & \multirow[b]{2}{*}{ Rescue solutior } \\
\hline & Mean & SEM & Mean & SEM & \\
\hline $\mathrm{K}$ & 7.34 & 0.05 & 117.96 & $2 \cdot 86$ & \\
\hline $\mathrm{Ca}$ & 4.15 & 0.27 & $155 \cdot 32$ & 3.94 & $300 \cdot 6$ \\
\hline $\mathrm{Na}$ & 27.86 & 0.97 & 18.90 & 0.49 & 68.97 \\
\hline $\mathrm{Mg}$ & 3.68 & 0.12 & 14.39 & 0.44 & \\
\hline P & ND & & ND & & 92.92 \\
\hline $\mathrm{Si}$ & 0.08 & 0.00 & 0.07 & 0.01 & \\
\hline $\mathrm{Al}$ & ND & & ND & & \\
\hline $\mathrm{Mn}$ & ND & & 0.35 & 0.09 & \\
\hline $\mathrm{Fe}$ & 0.31 & 0.08 & 0.10 & & \\
\hline $\mathrm{Cu}$ & ND & & ND & & \\
\hline $\mathrm{Zn}$ & ND & & ND & & \\
\hline As & ND & & ND & & \\
\hline Mo & ND & & ND & & \\
\hline $\mathrm{Cd}$ & ND & & ND & & \\
\hline $\mathrm{Pb}$ & ND & & ND & & \\
\hline $\mathrm{Cr}$ & ND & & ND & & \\
\hline
\end{tabular}

$\mathrm{ND}$, not detected.

*For details of procedures, see Materials and methods.

\section{The effect of Acer mono sap on osteoporosis-like symptoms}

To elucidate the beneficial effect of sap on osteoporosis-like symptoms, mice from the weaning (3 weeks old) to mature (10 weeks old) stage were fed low-calcium diets supplemented with increasing percentage solutions $(0,25,50$ and $100 \%)$ of sap, or a rescue solution containing a high concentration of calcium ions, and femur mineral densities were analysed using computer radiography (Fig. 1). The femurs of the normal group were bright and clear in radiographic images, while the corresponding images of the negative control group, which received commercial spring water, were dark and indistinct, which indicated that the mice had developed osteoporosis-like symptoms (Fig. 1 (A)). The rescue group (which received high calcium-containing water) exhibited improved femur brightness in radiographs. To determine the effect of sap on osteoporosis-like symptoms more precisely, the density of the distal (D) and proximal (P) femur heads was analysed using Direct View CR 500 software (Fig. 1 (B)). The densities of the distal and proximal femur heads of the normal group were significantly higher than all of the low-calcium diet groups. However, the bone densities of the 50 and $100 \%$ sap solution groups and the rescue group were significantly higher than the $25 \%$ sap solution and negative control group. Femur length was also analysed (Fig. $2(\mathrm{C})$ ), and we found that mice treated with commercial spring water alone, or a $25 \%$ sap solution, had significantly shorter femurs than normal mice. The femur lengths of the groups that received $50 \%$ or higher sap solutions were not significantly different from the normal group. The effect of sap on low-calcium diet-induced osteoporosis-like symptoms was further analysed by bone histomorphometry. The tibia was sectioned and stained with haematoxylin, and osteoid thickness was analysed (Fig. 2 (A)). The thickness of the negative group was significantly less than the normal group, and thickness gradually increased with increasing percentage sap solutions (Fig. 2 (B)). The tibia thicknesses of all of the low-calcium diet groups were significantly less than the normal group. Supplementation with $50 \%$ or greater sap solutions or rescue solution improved tibia thickness compared to the negative control group. The present results suggested that $50 \%$ or higher percentage sap solutions improve lowcalcium-induced osteoporosis-like symptoms.

\section{The effect of sap on calcium-processing gene expression}

Based on the previous experiment, administration of a $50 \%$ sap solution appeared to mitigate low-calcium diet-induced osteoporosis-like symptoms in mice. To begin to uncover the mechanism of the beneficial effect of sap on osteoporosis-like symptoms, we examined the expression of three duodenal and renal calcium-absorbing genes using real-time PCR. The expression of duodenal $C a B P-9 k$ was similar in mice that received sap, commercial spring water or a normal diet (Fig. 3 (A)). Mice that received the high calcium-containing rescue solution had significantly reduced expression levels of duodenal $C a B P-9 k$ compared with negative and normal dieted groups. The expression of duodenal TRPV6 was increased in the sap solution groups, but was decreased in the rescue group when compared with negative and normal dieted mice. In the kidney, the $C a B P-9 k$ expression levels of the 
(A) Sap of $A$. mono

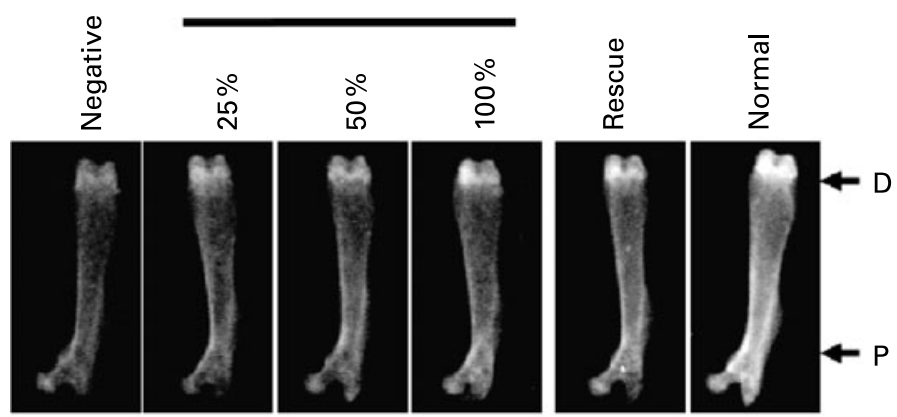

(B)

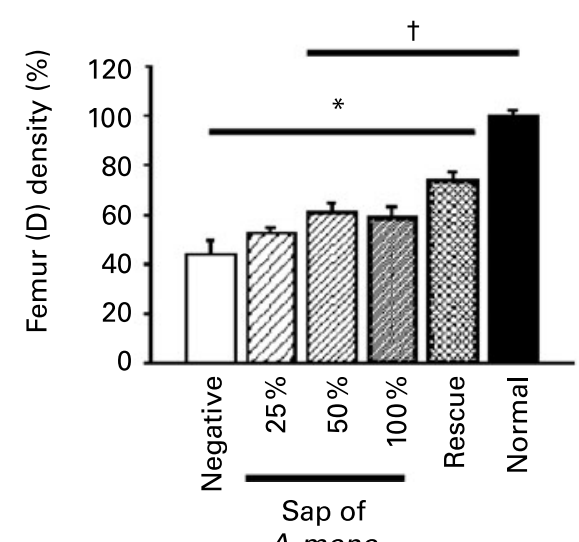

(C)

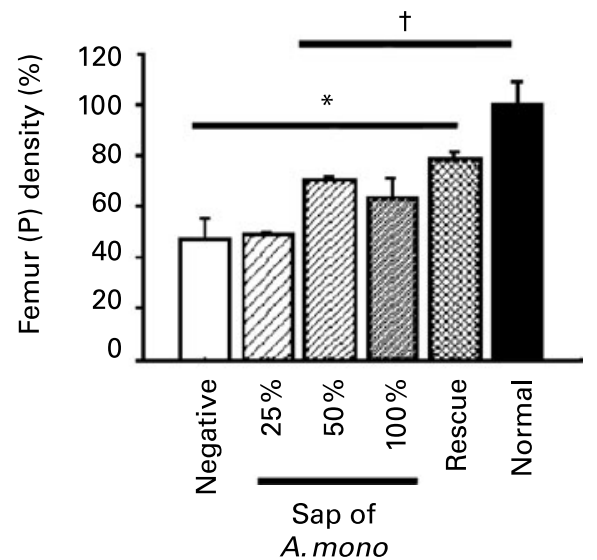

Fig. 1. The effect of Acer mono sap on osteoporosis-like symptoms assessed using bone radiography. Femurs were obtained from mice and analysed as described in the Materials and methods. (A), Representative femurs of each of the indicated treatment groups. (B, C) Bone density at the distal (B) and proximal (C) heads of all femurs (five per group). Values are means of duplicate measurements of all samples with their standard errors depicted by vertical bars. Data are expressed as a percentage of the density of a normal femur. D, distal head of femur; P, proximal head of femur; Negative, low-calcium diet plus commercial spring water; Normal, normal diet plus commercial spring water; Rescue, low-calcium diets plus high-calcium solution. Mean values were significantly different from those of the normal group: ${ }^{*} P<0.05$. Mean values were significantly different from those of the negative control group: $† P<0.05$.

sap solution and control mice were higher than those of the mice in the negative and rescue groups, and $C a B P-9 k$ expression was down-regulated in the negative and rescue groups compared to the normal group (Fig. 3 (B)). The expression of renal TRPV6 was not altered in any of the low-calcium diet groups. However, renal TRPV5 expression was decreased in the negative, sap solution and rescue groups compared to the normal group. These distinct patterns of regulation of duodenal and renal calcium-processing gene expression suggested that the mechanism that improves osteoporosis-like symptoms in the sap solution group involves not only augmentation of calcium levels, but also enhanced activity of the calcium active transport system.

\section{The effect of the sap on serum calcium and parathyroid} hormone levels

Serum calcium concentration was used to monitor changes in calcium homeostasis. The serum calcium concentrations of the negative group and the $25 \%$ sap solution group were lower than the normal group, while in the $50 \%$ or higher sap solution and rescue groups, serum calcium concentration was similar to normal levels (Table 2). The present result was consistent with the bone data given earlier. Serum PTH levels are also an indicator of osteoporosis ${ }^{(4,9)}$, as high PTH levels indicate that calcium ions are being released from the bone into serum to maintain calcium homeostasis. The negative and sap solution groups exhibited elevated serum PTH levels, while the rescue group had a significantly lower PTH level compared to the normal group.

\section{Discussion}

Maple syrup is a sweetener made from the sap of maple trees. It is often eaten with pancakes, waffles or French toast, and is used as an ingredient in baking and the preparation of desserts. A. mono is a kind of maple tree found in eastern Asia, and its sap can be ingested directly, without any processing. The sap of A. mono consists primarily of water, and contains minerals and sugars, similar to the sap of maple ${ }^{(1)}$. In the current study, we examined the pharmacological effect of the sap of $A$. mono. This sap is believed to be beneficial to bone health because of its high mineral content. We first examined the mineral content of sap, and compared it to commercial spring water. We showed that potassium, calcium and magnesium were present at high levels in sap. The level of calcium ions was 37 times higher, and magnesium was 3.9 times higher in the sap of $A$. mono than in commercial spring water. We hypothesized 
(A)

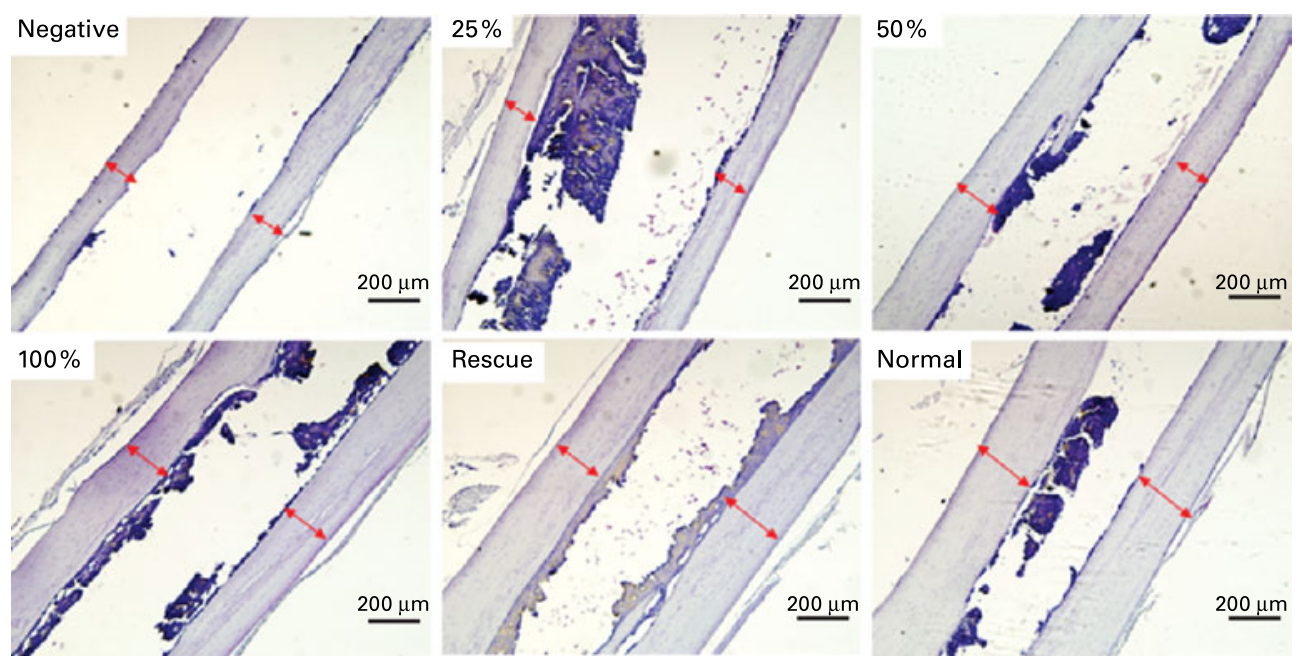

(B)

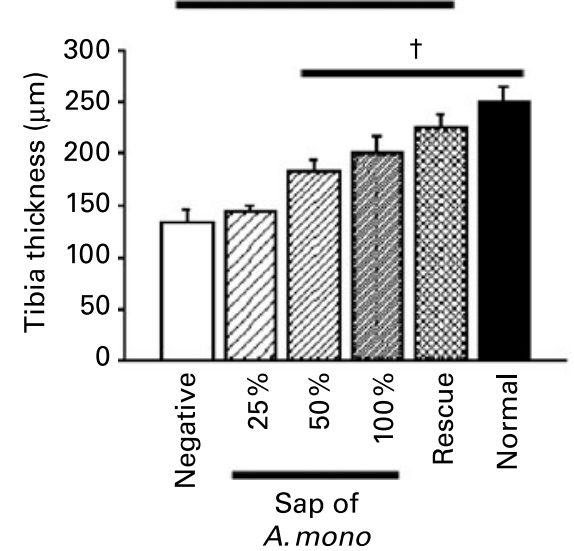

(C)

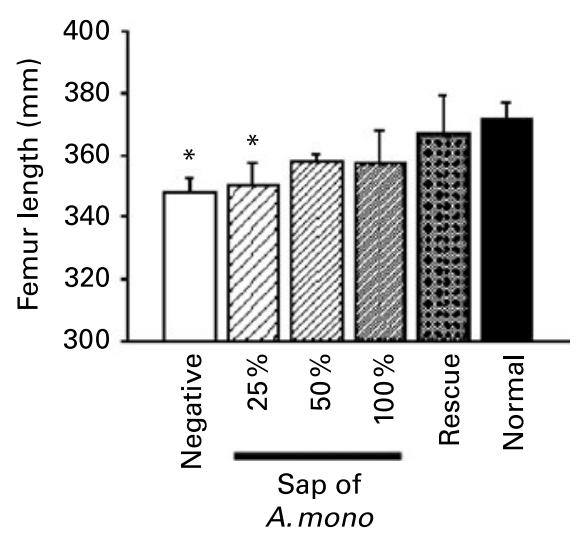

Fig. 2. The effect of Acer mono sap on osteoporosis-like symptoms assessed using bone histomorphometry. Tibias were removed from mice and processed as described in the Materials and methods. (A), Representative tibias of the indicated treatment groups. (B) Osteoid thickness taken at the middle of the bone for all femurs (five per group). $\leftrightarrow$, Measured thickness; space between the arrows represents the bone marrow. Values are means of duplicate measurements of all samples with their standard errors depicted by vertical bars. Data are expressed as a percentage the tibia thickness of the normal group. (C), Femur length analysed by radiography. Values are means of duplicate measurements of all samples with their standard errors depicted by vertical bars. Negative, low-calcium diet plus commercial spring water; Normal, normal diet plus commercial spring water; Rescue, low-calcium diets plus high-calcium solution. Mean values were significantly different from those of the normal group: ${ }^{\star} P<0.05$. Mean values were significantly different from those of the negative control group: $\dagger P<0.05$.

that it was the high calcium content of sap that prevented or improved the osteoporosis-like symptoms.

It is well known that calcium is essential to attain maximum bone mass ${ }^{(10,11)}$. Reduced calcium intake results in osteoporosis in man and in many other animal species ${ }^{(12)}$. Clinical and experimental nutritional secondary hyperparathyroidism rapidly develops in horses, dogs and cats fed diets high in phosphate and low in calcium ${ }^{(12)}$. Young rats and mice fed diets low in calcium develop osteoporosis-like symptoms, and ageing mice fed a high-calcium diet exhibit accelerated bone resorption with increased levels of dietary phosphate ${ }^{(12)}$. Similarly, ageing rats fed a diet with adequate calcium content developed progressively more severe osteoporosis as dietary phosphate was elevated ${ }^{(12)}$. Adult dogs fed diets high in phosphate but adequate levels of calcium developed rapid bone loss resembling osteoporosis, whereas young dogs developed severe nutritional secondary hyperparathyroidism characterized by fibrous osteodystrophy ${ }^{(12)}$. In the current study, we examined whether the high calcium content of the sap of A. mono would affect bone density when given as a supplement to a low-calcium diet. Although we demonstrated that administration of solutions of increasing percentages of sap increase bone density and osteoid thickness in a mouse model of induced osteoporosis-like symptoms, the sap supplement was less efficient in improving or preventing the symptoms when compared with a high-calcium solution or a normal diet. The present results suggested that in addition to supplying calcium ions, there are other factors involved in the beneficial effect of sap on osteoporosis-like symptoms. The other factor might be potassium which was present at 17 -fold higher concentration in sap than in commercial spring water. Potassium influences calcium homeostasis, particularly the urinary conservation and excretion of calcium ${ }^{(13)}$. Low-potassium diets increase urinary calcium losses while high-potassium diets reduce it $^{(13)}$. High-potassium intake ameliorates bone resorption in high-salt diets and is associated with a higher baseline bone 

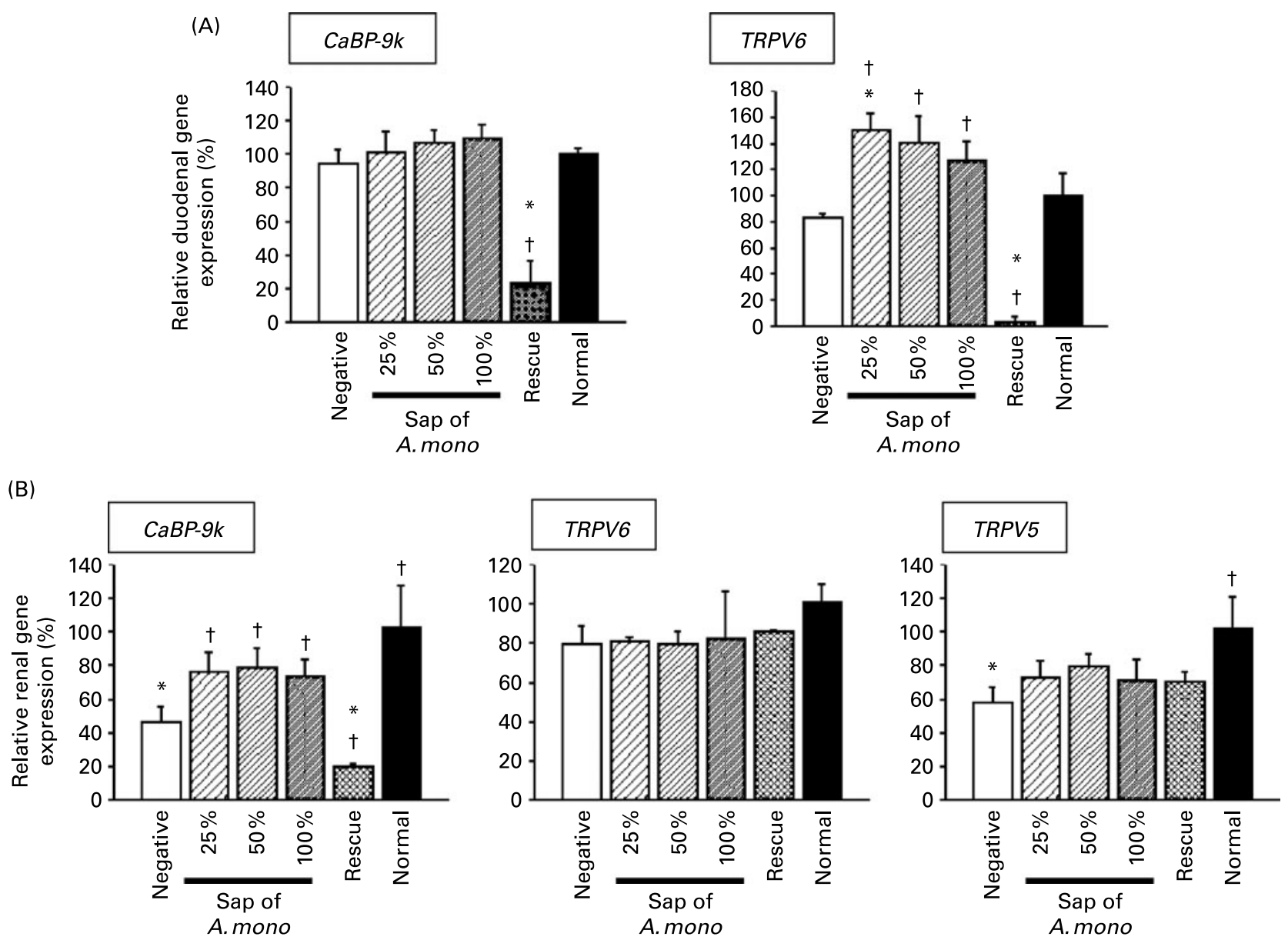

Fig. 3. The effect of Acer mono sap on the expression of calcium-processing genes. Duodenal (A; transient receptor potential vanilloid 6 (TRPV6), calbindin-D9k $(C a B P-9 k))$ and renal (B; TRPV6, transient receptor potential vanilloid 5 (TRPV5), CaBP-9k) mRNA were prepared from mice of the indicated treatment groups (five per group) as described in the Materials and methods. Relative gene expression of CaBP-9k, TRPV5 and TRPV6 was examined using real-time PCR. Values are means of duplicate measurements of all samples with their standard errors depicted by vertical bars. Data are expressed as a percentage of the expression of HPRT1, an internal control gene. Negative, low-calcium diet plus commercial spring water; Normal, normal diet plus commercial spring water; Rescue, low-calcium diets plus high-calcium solution. Mean values were significantly different from those of the normal group: ${ }^{\star} P<0.05$. Mean values were significantly different from those of the negative control group: $\uparrow P<0.05$.

mineral density and lower levels of bone loss ${ }^{(14,15)}$. Taken together, the present results suggest that the sap of $A$. mono improves low-calcium diet-induced osteoporosis-like symptoms via augmentation of mineral levels.

To clarify the mechanism of the sap's effect on osteoporosis-like symptoms, we examined the expression of calcium active transport genes. Based on the results of previous studies ${ }^{(9,16-18)}$, we examined the expression of TRPV5, TRPV6 and CaBP-9k. TRPV5 and TRPV6 are calcium channels found in the apical membranes of intestinal and renal epithelial cells, and have been proposed as the mediators of calcium uptake during trans-cellular calcium transport ${ }^{(19)}$. They are highly related proteins expressed mainly in cells involved in calcium absorption or re-absorption in the duodenum and kidney ${ }^{(20)}$. TRPV6 is distributed in the duodenum, jejunum, ileum and kidney, and in exocrine tissues such as the pancreas, prostate, mammalian gland and sweat gland ${ }^{(19,21,22)}$. Hormonal vitamin D-induced expression of TRPV5 occurs in rabbit renal epithelial cells, and TRPV5 has been identified in human, rat and mouse kidney. Dietary calcium also regulates TRPV6 mRNA expression of duodenocytes and renal distal convoluted tubules ${ }^{(7)}$. In the current study, we demonstrated that duodenal TRPV6 mRNA expression is induced by sap solutions, independent of the dose of sap. Renal TRPV6 was not influenced by any of the dietary beverage conditions. TRPV5 mRNA was induced by sap and the high-calcium rescue solution, but the level of expression was not significantly higher than normal levels. CaBP-9k is a cytosolic protein with a high affinity for calcium ions ${ }^{(23,24)}$. In mammals, a number of tissues and organs, including the intestine, uterus, placenta, kidney and bone, express $\mathrm{CaBP}$ $9 k^{(16-18,25-31)}$. Intestinal CaBP-9k is involved in intestinal calcium absorption and is regulated at the transcriptional and post-transcriptional levels by 1,25-dihydroxyvitamin D3 $\left(1,25-(\mathrm{OH})_{2} \mathrm{D}_{3}\right)$, the hormonal form of vitamin $\mathrm{D}$, in rodents ${ }^{(32-34)}$. It has also been shown that the expression of duodenal $C a B P-9 k$ may be linked to 1,25-dihydroxycholecalciferol in man ${ }^{(17)}$. Renal $C a B P-9 k$ is expressed at distal convoluted tubules, which are believed to facilitate calcium re-absorption ${ }^{(35)}$. In the current study, we showed that duodenal CaBP-9k mRNA levels were not altered by sap. 
Table 2. Serum calcium and parathyroid hormone (PTH) analysisł (Mean values with their standard errors)

\begin{tabular}{|c|c|c|c|c|}
\hline \multirow[b]{2}{*}{ Treatment } & \multicolumn{2}{|c|}{$\begin{array}{l}\text { Serum calcium } \\
\text { levels (mg/l) }\end{array}$} & \multicolumn{2}{|c|}{ Serum PTH (pg/ml) } \\
\hline & Mean & SEM & Mean & SEM \\
\hline Negative & $70 \cdot 1^{*}$ & $10 \cdot 1$ & $41 \cdot 78^{*}$ & 9.97 \\
\hline \multicolumn{5}{|c|}{ Sap of Acer mono } \\
\hline $25 \%$ & $72 \cdot 3^{*}$ & $8 \cdot 2$ & $35 \cdot 07^{\star}$ & $4 \cdot 34$ \\
\hline $50 \%$ & $86 \cdot 6$ & $5 \cdot 1$ & $52 \cdot 70^{*}$ & $17 \cdot 04$ \\
\hline $100 \%$ & $90 \cdot 2$ & $13 \cdot 2$ & $46 \cdot 98^{\star}$ & $9 \cdot 00$ \\
\hline Rescue & $86 \cdot 6$ & $6 \cdot 8$ & $5 \cdot 41^{*} \dagger$ & $1 \cdot 30$ \\
\hline Normal & 91.4 & 4.5 & $14 \cdot 20 \dagger$ & $5 \cdot 63$ \\
\hline
\end{tabular}

Mean values were significantly different from those of the normal group: ${ }^{\star} P<0.05$. Mean values were significantly different from those of the negative control group: $\dagger P<0.05$

†For details of procedures, see Materials and methods.

However, sap solution increased renal $C a B P-9 k$ mRNA expression. The high calcium-containing rescue solution significantly decreased duodenal $C a B P-9 k$ and TRPV6 transcription. In addition, it has previously been shown that high calcium intake attenuates $C a B P-9 k$ and TRPV6 gene expression in mice ${ }^{(36)}$. Thus, while sap appeared to regulate duodenal TRPV6 and renal $C a B P-9 k$ expression, this effect was different from that of the rescue solution. The present result indicated that the underlying mechanism of regulation of these genes by sap may not involve calcium ions. If the high calcium content of sap was involved in the regulation of $C a B P-9 k$ and TRPV6, one would also expect the effect of sap on the expression patterns of these genes to be similar to previous studies ${ }^{(9,36)}$.

Generally, a calcium-deficient diet decreases serum calcium concentration and accelerates PTH secretion ${ }^{(37)}$. In the current study, we demonstrated that the serum calcium levels of mice that received a $50 \%$ or higher sap solution were similar to mice that were fed a normal diet. The present results suggest that the amount of calcium in a $50 \%$ sap solution is sufficient to maintain normal calcium homeostasis. PTH plays a major role in regulating calcium homeostasis. PTH regulates the conversion of 25 -hydroxyvitamin $\mathrm{D}$ to the active metabolite $1,25-(\mathrm{OH})_{2} \mathrm{D}_{3}$. PTH also activates dihydropyridine-sensitive channels that mediate calcium entry. It has also been suggested that microtubule-dependent exocytosis stimulated by PTH is required for the activation of calcium channels and calcium influx ${ }^{(38)} \cdot 1,25-(\mathrm{OH})_{2} \mathrm{D}_{3}$ inhibits PTH secretion and parathyroid cell proliferation through the action of the vitamin $\mathrm{D}$ receptor ${ }^{(39,40)}$. It has also been shown that PTH secretion and bone mineralization correlate with calcium levels, rather than the activation state of the $1,25-(\mathrm{OH})_{2} \mathrm{D}_{3}$ receptor signalling pathway ${ }^{(41,42)}$. In the current study, serum PTH was up-regulated by a low-calcium diet compared to the normal group; however, the mice in the rescue group showed significantly lower serum PTH levels. The present results suggest that sap improves osteoporosis-like symptoms via a different mechanism than the high calcium-containing solution, similar to the regulation of the calcium-processing genes.

In summary, the positive effect of sap on osteoporosislike symptoms was evaluated by measuring serum calcium concentrations, femur density and length, and by a histological examination. Serum calcium levels were significantly lower in mice that received a low-calcium diet supplemented with commercial spring water, and in the $25 \%$ sap solution group compared to the normal group, but not in the 50 and $100 \%$ sap solution groups, or the rescue group. Femur density and length were significantly reduced in the negative and $25 \%$ sap solution groups. The present results imply that a $50 \%$ or higher sap solution could ameliorate osteoporosis-like symptoms induced by a low-calcium diet. The results of the histological analysis correlated with the bone density results. In addition, we examined the expression of calcium-processing genes in the duodenum and kidney, and showed that duodenal TRPV6 and renal $C a B P-9 k$ were upregulated by sap in a dose-independent manner. We propose that the sap of $A$. mono may improve low-calcium dietinduced osteoporosis-like symptoms by augmenting mineral levels in the body.

\section{Acknowledgements}

This work was supported by the Ministry of Education and Human Resources Development (MOE), the Ministry of Commerce, Industry and Energy (MOCIE) and the Ministry of Labor (MOLAB) through the fostering project of the Laboratory of Excellency. In addition, the authors appreciate a grant provided by Korea Forest Research Institute. G.-S. L., H.-S. B., I.-G. C., H.-Y. K. and E.-B. J. designed the research; G.-S. L., H.-S. B., M.-H. K., B.-M. L., S.-H. K., E.-M. J., K.-S. G., H. -J. J. and H. -J. L. performed the research; G.S. L., H.-S. B. and E.-B. J. analysed the data; and G.-S. L. and E.-B. J. wrote the paper. The authors declare no conflicts of interest.

\section{References}

1. Angeles GBJ, Bond JS, Boyer TJ, et al. (2004) The cohesiontension theory. New Phytol 163, 451-452.

2. Kunkel G (1984) Plants for Human Consumption. Koenigstein: Koeltz Scientific Books.

3. Chopra RN, Nayar SL \& Chopra IC (1986) Glossary of Indian Medicinal Plants. New Delhi: Council of Scientific and Industrial Research.

4. Pettifor JM, Marie PJ, Sly MR, du Bruyn DB, Ross F, Isdale JM, de Klerk WA \& van der Walt WH (1984) The effect of differing dietary calcium and phosphorus contents on mineral metabolism and bone histomorphometry in young vitamin D-replete baboons. Calcif Tissue Int 36, 668-676.

5. Diepens RJ, den Dekker E, Bens M, Weidema AF, Vandewalle A, Bindels RJ \& Hoenderop JG (2004) Characterization of a murine renal distal convoluted tubule cell line for the study of transcellular calcium transport. Am J Physiol Renal Physiol 286, F483-F489.

6. Hoenderop JG, Nilius B \& Bindels RJ (2003) Epithelial calcium channels: from identification to function and regulation. Pflugers Arch 446, 304-308.

7. Van Cromphaut SJ, Rummens K, Stockmans I, Van Herck E, Dijcks FA, Ederveen AG, Carmeliet P, Verhaeghe J, Bouillon R \& Carmeliet G (2003) Intestinal calcium transporter genes are upregulated by estrogens and the reproductive cycle through vitamin D receptor-independent mechanisms. J Bone Miner Res 18, $1725-1736$. 
8. Lee GS \& Jeung EB (2007) Uterine TRPV6 expression during the estrous cycle and pregnancy in a mouse model. Am J Physiol 293, E132-E138.

9. Lee GS, Lee KY, Choi KC, Ryu YH, Paik SG, Oh GT \& Jeung EB (2007) A phenotype of a calbindin-D9k gene-knockout is compensated for by the induction of other calcium-transporter genes in a mouse model. J Bone Miner Res 22, 1968-1978.

10. Bunker VW (1994) The role of nutrition in osteoporosis. $\mathrm{Br} J$ Biomed Sci 51, 228-240.

11. Tranquilli AL, Lucino E, Garzetti GG \& Romanini C (1994) Calcium, phosphorus and magnesium intakes correlate with bone mineral content in postmenopausal women. Gynecol Endocrinol 8, 55-58.

12. Anderson MP, Hunt RD, Griffiths HJ, McIntyre KW \& Zimmerman RE (1977) Long-term effect of low dietary calcium:phosphate ratio on the skeleton of Cebus albifrons monkeys. J Nutr 107, 834-839.

13. Nieves JW (2005) Osteoporosis: the role of micronutrients. Am $J$ Clin Nutr 81, 1232S-1239S.

14. Harrington M \& Cashman KD (2003) High salt intake appears to increase bone resorption in postmenopausal women but high potassium intake ameliorates this adverse effect. Nutr Rev 61, 179-183.

15. Tucker KL, Hannan MT \& Kiel DP (2001) The acid-base hypothesis: diet and bone in the Framingham Osteoporosis Study. Eur J Nutr 40, 231-237.

16. Lee GS, Choi KC \& Jeung EB (2006) Glucocorticoids differentially regulate expression of duodenal and renal calbindin-D9k through glucocorticoid receptor-mediated pathway in mouse model. Am J Physiol 290, E299-E307.

17. Walters JR, Howard A, Lowery LJ, Mawer EB \& Legon S (1999) Expression of genes involved in calcium absorption in human duodenum. Eur J Clin Invest 29, 214-219.

18. Wissenbach U \& Niemeyer BA (2007) TRPV6. In Transient Receptor Potential (TRP) Channels. Handbook of Experimental Pharmacology, vol. 179, pp. 221-234 [V Flockerzi and B Nilius, editors]. Berlin: Springer.

19. den Dekker E, Hoenderop JG, Nilius B \& Bindels RJ (2003) The epithelial calcium channels, TRPV5 \& TRPV6: from identification towards regulation. Cell Calcium 33, 497-507.

20. Song Y, Peng X, Porta A, Takanaga H, Peng JB, Hediger MA, Fleet JC \& Christakos S (2003) Calcium transporter 1 and epithelial calcium channel messenger ribonucleic acid are differentially regulated by 1,25 dihydroxyvitamin D3 in the intestine and kidney of mice. Endocrinology 144, 3885-3894.

21. van Abel M, Hoenderop JG, van der Kemp AW, van Leeuwen JP \& Bindels RJ (2003) Regulation of the epithelial $\mathrm{Ca}^{2+}$ channels in small intestine as studied by quantitative mRNA detection. Am $J$ Physiol Gastrointest Liver Physiol 285, G78-G85.

22. Weber K, Erben RG, Rump A \& Adamski J (2001) Gene structure and regulation of the murine epithelial calcium channels ECaC1 and 2. Biochem Biophys Res Commun 289, 1287-1294.

23. Christakos S, Gabrielides C \& Rhoten WB (1989) Vitamin Ddependent calcium binding proteins: chemistry, distribution, functional considerations, and molecular biology. Endocr Rev 10, 3-26.

24. Kumar R, Wieben E \& Beecher SJ (1989) The molecular cloning of the complementary deoxyribonucleic acid for bovine vitamin D-dependent calcium-binding protein: structure of the full-length protein and evidence for homologies with other calcium-binding proteins of the troponin-C superfamily of proteins. Mol Endocrinol 3, 427-432.

25. An BS, Choi KC, Kang SK, Lee GS, Hong EJ, Hwang WS \& Jeung EB (2003) Mouse calbindin- $\mathrm{D}_{9 \mathrm{k}}$ gene expression in the uterus during late pregnancy and lactation. Mol Cell Endocrinol 205, 79-88.
26. An BS, Kang SK, Shin JH \& Jeung EB (2002) Stimulation of calbindin- $D_{9 \mathrm{k}}$ mRNA expression in the rat uterus by octylphenol, nonylphenol and bisphenol. Mol Cell Endocrinol 191, $177-186$

27. Choi KC, Leung PC \& Jeung EB (2005) Biology and physiology of Calbindin-D9k in female reproductive tissues: involvement of steroids and endocrine disruptors. Reprod Biol Endocrinol 3, 66

28. Hong EJ, Choi KC \& Jeung EB (2004) Induction of calbindinD9k messenger RNA and protein by maternal exposure to alkylphenols during late pregnancy in maternal and neonatal uteri of rats. Biol Reprod 71, 669-675.

29. Lee GS, Kim HJ, Jung YW, Choi KC \& Jeung EB (2005) Estrogen receptor alpha pathway is involved in the regulation of Calbindin-D9k in the uterus of immature rats. Toxicol Sci 84, 270-277.

30. Nguyen TH, Lee GS, Ji YK, Choi KC, Lee CK \& Jeung EB (2005) A calcium binding protein, calbindin-D9k, is mainly regulated by estrogen in the pituitary gland of rats during estrous cycle. Brain Res Mol Brain Res 141, 166-173.

31. Yun SM, Choi KC, Kim IH, An BS, Lee GS, Hong EJ, Oh GT \& Jeung EB (2004) Dominant expression of porcine CalbindinD9k in the uterus during a luteal phase. Mol Reprod Dev 67, 251-256.

32. Darwish HM \& DeLuca HF (1992) Identification of a 1,25-dihydroxyvitamin D3-response element in the $5^{\prime}$-flanking region of the rat calbindin D-9k gene. Proc Natl Acad Sci U S A 89, 603-607.

33. Roche C, Bellaton C, Pansu D, Miller A 3rd \& Bronner F (1986) Localization of vitamin D-dependent active $\mathrm{Ca}^{2+}$ transport in rat duodenum and relation to CaBP. Am J Physiol 251, G314-G320.

34. Wasserman RH \& Fullmer CS (1989) On the molecular mechanism of intestinal calcium transport. Adv Exp Med Biol 249, 45-65.

35. Peng JB, Chen XZ, Berger UV, Vassilev PM, Brown EM \& Hediger MA (2000) A rat kidney-specific calcium transporter in the distal nephron. J Biol Chem 275, 28186-28194.

36. Van Cromphaut SJ, Dewerchin M, Hoenderop JG, Stockmans I, Van Herck E, Kato S, Bindels RJ, Collen D, Carmeliet P, Bouillon R \& Carmeliet G (2001) Duodenal calcium absorption in vitamin D receptor-knockout mice: functional and molecular aspects. Proc Natl Acad Sci U S A 98, 13324-13329.

37. Kato S, Mano T, Kobayashi T, Yamazaki N, Himeno Y, Yamamoto K, Itoh M, Harada N \& Nagasaka A (2002) A calciumdeficient diet caused decreased bone mineral density and secondary elevation of estrogen in aged male rats - effect of menatetrenone and elcatonin. Metabolism 51, 1230-1234.

38. Bacskai BJ \& Friedman PA (1990) Activation of latent $\mathrm{Ca}^{2+}$ channels in renal epithelial cells by parathyroid hormone. Nature 347, 388-391.

39. Carling T, Rastad J, Szabo E, Westin G \& Akerstrom G (2000) Reduced parathyroid vitamin D receptor messenger ribonucleic acid levels in primary and secondary hyperparathyroidism. $J$ Clin Endocrinol Metab 85, 2000-2003.

40. Demay MB, Kiernan MS, DeLuca HF \& Kronenberg HM (1992) Sequences in the human parathyroid hormone gene that bind the 1,25-dihydroxyvitamin D3 receptor and mediate transcriptional repression in response to 1,25-dihydroxyvitamin D3. Proc Natl Acad Sci U S A 89, 8097-8101.

41. Li YC, Bolt MJ, Cao LP \& Sitrin MD (2001) Effects of vitamin $D$ receptor inactivation on the expression of calbindins and calcium metabolism. Am J Physiol 281, E558-E564.

42. Song CZ, Tian X \& Gelehrter TD (1999) Glucocorticoid receptor inhibits transforming growth factor-beta signaling by directly targeting the transcriptional activation function of Smad3. Proc Natl Acad Sci U S A 96, 11776-11781. 